\title{
Quando o velho encontra o novo: uma análise da descentralização proposta com as subprefeituras nas cidades de São Paulo e Rio de
} Janeiro

Eduardo José Grin

Fundação Getulio Vargas (FGV)

Camila Romero Lameirão

Universidade Federal de Goiás (UFG)

Teoricamente $\mathrm{o}$ artigo discute se inovações institucionais em estruturas governamentais podem alimentar e serem apoiadas por práticas políticas tradicionalmente existentes. Empiricamente analisa-se a descentralização, por meio da implantação das subprefeituras nas cidades do Rio de Janeiro e São Paulo. Mostra-se como gradativamente as subprefeituras transformaram-se em recurso político para os prefeitos constituírem sua política de alianças na Câmara Municipal. O pluralismo e o institucionalismo histórico são o suporte teórico deste estudo qualitativo baseado em most-different cases: enfatiza-se a variação sobre as variáveis independentes e busca-se evitar a variação sobre os resultados. $O$ objetivo é analisar a semelhança na forma como as subprefeituras serviram para os prefeitos paulista e carioca construírem suas coalizões políticas dominantes. Conclui-se que a descentralização nem sempre é virtuosa, pois, em contextos em que vereadores têm influência e controle sobre regiões da cidade, existem incentivos à manutenção de práticas políticas institucionalizadas de patronagem governamental para obter apoio parlamentar.

Palavras-chave: descentralização administrativa, política de governo, democracia representativa, coalisão política, inovação, controle social, subprefeitura

[Artigo recebido em 11 de janeiro de 2017. Aprovado em 14 de agosto de 2018.] 
Cuando el viejo encuentra lo nuevo: un análisis de la descentralización propuesta con las subprefecturas en las ciudades de São Paulo y Río de Janeiro

Teóricamente el artículo discute sí las innovaciones institucionales en estructuras gubernamentales pueden alimentar y ser apoyadas por prácticas políticas tradicionalmente existentes. Empíricamente se analiza la descentralización, a través de la implantación de las Subprefecturas en las ciudades de Rio de Janeiro y São Paulo. Se muestra como gradualmente las Subprefecturas fueron transformadas en recurso político para los alcaldes construir sus políticas de alianzas en el Ayuntamiento Municipal. El pluralismo y el institucionalismo histórico son los suportes teóricos de eso estudio cualitativo basado en most-different cases: es enfatizado la variación sobre las variables independientes y sí busca evitar la variación en torno de los resultados. El objetivo es analizar la semejanza en la forma como las Subprefecturas fueron útiles para los alcaldes paulista y carioca construir sus coaliciones políticas dominantes. Es concluido que la descentralización no es siempre virtuosa, pues en contextos donde los regidores tienen influencia y control sobre regiones de la ciudad existen incentivos para la manutención de prácticas políticas institucionalizadas de patronazgo gubernamental hacia obtener apoyo parlamentario.

Palabras clave: descentralización administrativa, política de gobierno, democracia representativa, coalición política, innovación, control social, subprefectura

When the old meets the new: an analysis of the decentralization proposed with the subprefeituras in the cities of São Paulo and Rio de Janeiro

Theoretically this article discusses if institutional innovations in governmental structures can feed and to be supported by political practices traditionally existent. Empirically we analyze the decentralization through the implementation of the Subprefectures in Rio de Janeiro and São Paulo cities. We show how gradually the Subprefectures became political resources for the mayors to constitute their policy of alliance at the City Council. The pluralism and historic institutionalism are the theoretical support of this qualitative study based on most-different cases: we stress the variation about the independent variable seeking to avoid the variation over the results. The goal is to analyze the similarity of the manner how the Subprefectures served to the paulista and carioca mayors build their dominant political coalition. We conclude that the decentralization not always is virtuous because in settings where aldermen have influence and control over regions of the city there are inducements to the maintenance of institutionalized political practices of governmental patronage to get parliamentarian support.

Keywords: administrative decentralization, government policy, representative democracy, political coalition, innovation, social control, subprefeitura 


\section{Introdução}

Descentralização é um daqueles conceitos carregados de viés normativo, pois costuma associar-se à visão de que seus efeitos serão positivos ao aproximar o poder público das demandas da sociedade. Todavia, pode acontecer o contrário se a descentralização de poder produz incentivos que contribuem para ampliar a patronagem com os recursos públicos (ARRETCHE, 1996). Este artigo analisa a implantação das dubprefeituras nas cidades de São Paulo e Rio de Janeiro com essa perspectiva.

Nas duas experiências, o discurso oficial apresentou-as como inovações para melhorar a gestão local ou ampliar a democracia participativa frente aos limites que se julgavam existir na democracia representativa, sobretudo na ação dos vereadores. Contudo, ainda que os dois arranjos organizacionais fossem distintos em suas concepções, passaram a assemelhar-se como recurso político estratégico do governo para obter apoio dos vereadores e constituir sua base de apoio parlamentar. Igualmente, para impulsionar a carreira política de quadros vinculados ao prefeito ou a altos cargos do secretariado municipal já inseridos, ou que pretendiam ingressar, na competição eleitoral local.

Nas duas cidades, buscava-se criar canais mais diretos de relação entre o governo e os bairros, visando diminuir a intermediação dos vereadores, o que serviria para instituir um novo modelo de gestão urbana com mais capacidade de resposta. Sendo esse o objetivo geral das subprefeituras nas duas cidades, a questão teórica que esse trabalho busca responder é: inovações institucionais em estruturas governamentais podem alimentar e ser apoiada por práticas políticas tradicionalmente existentes? O argumento é que a "lógica dos vereadores" acabou prevalecendo, pois as subprefeituras passaram a ser meios essenciais para os governos comporem suas coalizões de apoio na Câmara Municipal.

O presente artigo busca contribuir para um tema pouco explorado na literatura nacional de Ciência Política e Administração Pública: analisar experiências de processos de descentralização intramunicipal como formato político-administrativo. Sob os incentivos da Constituição de 1988, esse modelo difundiu-se entre várias cidades brasileiras, sobretudo capitais, mas persiste ainda pouco estudado. A pesquisa acadêmica das experiências de descentralização, ou desconcentração, político-administrativa na gestão municipal, com seus impactos na organização do Estado em nível local, é ainda muito reduzida. Especialmente se o objetivo é analisar o jogo de poder e a ação dos atores políticos no interior das instituições políticas, comparando diferentes cidades. 
Embora existam alguns trabalhos sobre o tema, a ênfase da literatura em Ciência Política e Administração Pública, comumente, prioriza a análise das relações intergovernamentais, de modo que o nível de descentralização de um ente como o município é avaliado quando comparado em sua relação com um ente maior (estados ou União). Por outro lado, os estudos mais circunscritos à dinâmica de governo municipal tendem a enfatizar os processos participativos como a principal inovação nos governos subnacionais, e seus impactos na gestão local. As análises recaem mais sobre os aspectos sociopolíticos do poder local, nos termos utilizados pelos estudiosos do tema, e menos sobre organização e funcionamento do governo local na gestão do seu território.

Há, portanto, uma escassez de investigações sobre descentralização na gestão intramunicipal, em específico nas capitais, e os impactos que produz no jogo político e administrativo local, na organização da gestão dos territórios e na oferta de serviços públicos. O estudo visa explorar essa agenda de pesquisa, produzindo uma análise sobre os dois maiores municípios brasileiros.

Este é um estudo comparado que se vale do que Gerring (2007, p. 139-140) chama de most-different cases: a variação sobre as variáveis independentes é valorizada, enquanto se busca evitar a variação sobre os resultados. Antes que procurar por casos que são muitos similares, buscam-se casos que são muito diferentes. $O$ pesquisador dedica-se a identificar casos em que apenas uma variável independente $(\mathrm{Xi})$, bem como a variável dependente $(\mathrm{Y})$ covariam, enquanto os demais fatores plausíveis $(\mathrm{X} 2 \mathrm{a}-\mathrm{d})$ mostram diferentes valores. Os casos A e B são julgados most-different, embora eles sejam similares em dois aspectos essenciais: a variável causal de interesse e o resultado.

A situação aqui analisada se encaixa nessa técnica para a escolha de casos, pois o objetivo é verificar se a implantação das subprefeituras (Xi) como variável independente covaria, em ambos casos, com a sua utilização pelo governo municipal para compor sua política de alianças como variável dependente. Outros aspectos que distinguem as duas cidades, como, por exemplo, os partidos no governo (PFL no Rio de Janeiro e PT em São Paulo), desenho institucional e regras legais e administrativas que definem as subprefeituras, são condições contextuais em ambos os casos.

As técnicas de pesquisa utilizadas foram basicamente duas: análise documental e entrevistas. Em termos do período de análise para comparar os dois casos, em São Paulo adotou-se o governo petista de Marta Suplicy (2001-2004), enquanto no Rio de Janeiro os quatro governos do PFL iniciados com a gestão Cesar Maia (1993- 
1996), seguidos de Paulo Conde (1997-2000) e os dois seguintes de Maia (20012004, 2005-2008)1.

Além desta introdução, o artigo está organizado como segue. A primeira seção apresenta as bases gerais das finalidades das subprefeituras como inovação governamental em São Paulo e Rio de Janeiro. Segue-se apresentando a revisão da literatura, que se apoia no pluralismo (como agem os atores políticos e se conforma a coalizão política dominante) e no institucionalismo histórico, que aporta conceitos úteis para analisar a persistência de práticas políticas enraizadas nas instituições políticas.

As duas partes seguintes analisam as subprefeituras em São Paulo e Rio de Janeiro e a forma como a ação dos vereadores e do(a) prefeito(a) gradativamente transformou a gestão dos bairros em recurso político para atender os interesses dos parlamentares junto às suas clientelas locais. A conclusão retoma o argumento central do artigo, e compara os dois casos, mostrando como funcionou a "lógica da vereança". Esse foi o mecanismo explicativo que aproximou a inovação das subprefeituras da prática política institucionalizada dos governos de constituírem sua política de alianças na Câmara Municipal por meio da concessão de espaços de poder nos bairros aos vereadores.

\section{As subprefeituras como proposta para inovar a gestão municipal}

Em São Paulo, a implantação das subprefeituras, a partir de 2002, foi a principal mudança na organização do poder público municipal desde a criação das administrações regionais (ARs) ${ }^{2}$ em 1965. O modelo se baseou no projeto da gestão petista de Luiza Erundina (1989-1992) (SADER, 1992; MARTINS, 1997). Como os Governos Paulo Maluf (1992-1996) e Celso Pitta (1997-2000) não tinham interesse na sua implantação, o tema só voltou à agenda na eleição municipal em 2000.

A crise política e administrativa das ARs no Governo Pitta ampliou o consenso entre vários atores políticos de que as subprefeituras seriam a solução para a gestão regional, sobretudo para pôr fim à influência dos vereadores e dos administradores regionais que indicavam. Assim, na eleição de 2000, conforme o programa de governo da Coligação Muda São Paulo (PT-PCdoB), as subprefeituras

\footnotetext{
${ }^{1}$ A comparação de um mandato do PT em São Paulo (2001-2004) com quatro mandatos do PFL no Rio de Janeiro (1993-2007) não prejudica o argumento central desse artigo. Como será visto, as escolhas realizadas pelo governo petista foram gradativamente assumidas na gestão do PFL na prefeitura carioca antes do que em São Paulo. 0 importante é com as Subprefeituras, nos dois casos, assumiu relevância a "lógica da vereança" para formar a coalizão política dominante. Assim, nas duas experiências, em tempos distintos, houve uma convergência quanto à estratégia para constituir a política de alianças na Câmara Municipal.

${ }^{2}$ As ARs eram estruturas desconcentradas, voltadas apenas para serviços de zeladoria urbana e subordinadas à Secretaria de Administração das Regionais como órgãos de segundo escalão.
} 
democratizariam o poder político, reconstruiriam capacidades estatais e ampliariam a governabilidade na gestão municipal. Além do apoio político, havia suporte na Lei Orgânica Municipal: “a administração municipal será exercida, em nível local, através de Subprefeituras, na forma estabelecida em lei, definindo atribuições, número, limites territoriais, competências e processo de eleição do Subprefeito".

As subprefeituras seriam "centros regionais com poder de decisão" para organizar a gestão local em novas bases democráticas em face de sua proximidade dos cidadãos (SPOSATI, 2001; GARIBE, 2004). O diálogo direto com a população reduziria a influência clientelista dos vereadores que existia na captura das ARs (SPOSATI, 2002; SANTOS; BARRETA, 2004). A proposta associava descentralização territorial com fóruns de democracia participativa para compensar localmente o que consideravam serem limites da democracia representativa para transformar o poder público em favor da sociedade.

Conforme o programa de governo, a forma como os vereadores historicamente se apropriaram das ARs impossibilitava separar o Executivo e o Legislativo na gestão municipal. O Legislativo deveria aprimorar os projetos do governo, fiscalizar o Executivo e tratar de temas globais da cidade. Nas regiões, a gestão, com participação popular e controle social, caberia às subprefeituras. Essa era a visão do PT, visando equilibrar a novidade da descentralização e os papéis atribuídos aos vereadores, de modo a garantir autonomia política e administrativa às subprefeituras.

As subprefeituras cariocas surgem em 1993 formalmente denominadas de áreas de planejamento (APs) e, diferentemente de São Paulo, não foram criadas por meio de processo legislativo formalizado. O surgimento ocorreu por decreto, ou seja, um ato unilateral do então Prefeito Cesar Maia, que logo nos primeiros dias de exercício no cargo distribuiu representantes do seu governo entre as diferentes regiões da cidade, e passou a denominá-los de subprefeitos. À época, o prefeito justificou que o seu intento serviria para tornar a prestação dos serviços mais ágil e adequada às demandas locais, aproximando a prefeitura da sociedade.

Com esse propósito, as subprefeituras surgiram no município com a atribuição de supervisionar as diversas regiões administrativas (RAs). As RAs constituem uma divisão administrativa do Executivo local ainda em vigência, estabelecida no Estado da Guanabara3 pelo Governador Carlos Lacerda (1960-1965). A Lei Orgânica Municipal define no art. 124 que "a Administração Regional é o órgão de representação do prefeito e de coordenação e supervisão da atuação dos demais órgãos do Poder Executivo na área de sua circunscrição". Como estão

${ }^{3}$ O Estado da Guanabara constituiu-se no território do atual município do Rio de Janeiro a partir de 1960, quando o Distrito Federal foi transferido para Brasília. Em 1975 houve a fusão dos estados da Guanabara e do Rio de Janeiro e, então, o primeiro, tornou-se o município do Rio de Janeiro, capital do estado homônimo. 
previstas na Lei Orgânica, as RAs só podem ser extintas, ou formalmente substituídas pelas subprefeituras, por meio de projeto de lei, com tramitação obrigatória na Câmara dos Vereadores.

Pelas atribuições de que foram encarregadas diretamente por Maia, as subprefeituras se sobreporiam às estruturas das RAs, absorvendo, em tese, as funções de representação do prefeito e de coordenação da prestação dos serviços públicos do município em cada localidade. As subprefeituras, no entanto, teriam um caráter mais informal, visto que suas competências derivariam de delegação expressa do prefeito. Essa sobreposição, entre RAs e subprefeituras, persiste até os dias atuais no município carioca, e pode-se dizer que, ao longo de diferentes governos, não houve um padrão, mas sim uma intensa variação na relação entre essas duas representações da prefeitura.

Desde sua fundação, passaram-se mais de duas décadas, e, nesse período, além de Cesar Maia, que governou a cidade por três mandatos (1993-1996, 2001-2004 e 2005-2008), Luiz Paulo Conde (1997-2000) e Eduardo Paes (2009-2012, 20132016), ambos antigos aliados políticos de Maia, mantiveram as subprefeituras durante todo o tempo em vigência no município carioca. Essa trajetória, embora ininterrupta, foi marcada por movimentos que não produziram um sistema padronizado ou estável. O número de subprefeituras oscilou bastante a cada novo mandato. Além disso, os procedimentos de ligação dessas representações locais da prefeitura com os demais órgãos administrativos do município ${ }^{4}$, por não serem regulamentados, têm sido, do ponto de vista institucional, frágeis e dependentes das circunstâncias políticas de cada governo.

\section{Atores políticos e suas estratégias em contexto de mudanças políticas e administrativas}

Para responder a pergunta do artigo (inovações institucionais em estruturas governamentais podem alimentar e ser apoiadas por práticas políticas tradicionais?), o pluralismo e o neoinstitucionalismo histórico são os suportes teóricos. Na primeira abordagem, enfatiza-se a ação dos atores políticos e sua relação com as estruturas de poder governamental. Na segunda, aborda-se a convivência entre

\footnotetext{
${ }^{4}$ De acordo com o artigo 142 da Lei Orgânica, os órgãos integrantes da administração direta são de: I- direção e assessoramento superior; II- direção e assessoramento intermediários; III- execução. No § 10 consta que são órgãos de direção superior, providos de respectivo assessoramento, as Secretarias Municipais, a ProcuradoriaGeral do Município, a Secretaria Geral e a Diretoria-Geral de Administração da Câmara Municipal e a Secretaria do Tribunal de Contas. O § 3 ㅇ indica, por sua vez, que são órgãos de execução aqueles incumbidos de realização dos programas e projetos determinados pelos órgãos de direção. Esses constituem o núcleo da administração, ao passo que os órgãos de execução representam suas instâncias concebidas como descentralizadas e regionalizadas.
} 
inovação administrativa e a persistência de práticas políticas institucionalizadas nas estruturas governamentais.

\section{Atores políticos e sua inserção na dinâmica política governamental}

O pluralismo busca conhecer, nas issue areas, como agem os atores políticos, quais são seus interesses e recursos políticos, visando a que o governo os incorpore. Nos "temas-chave" conformam-se arenas decisórias em que há atores e interesses persistentes que influem na formação de coalizões políticas, distribuem poder e permitem explicar as decisões governamentais (DAHL, 1958, 1989; POLSBY, 1960).

Nesse processo, grupos políticos à frente do governo detêm capacidades desiguais em relação a outros grupos, pois controlam recursos políticos como nomear cargos, gerar contratos e distribuir empregos. Esses são meios centrais para forjar acordos menos instáveis, pois a política caracteriza-se por alianças efêmeras para o exercício do poder (DAHL, 1961; POLSBY, 1960). Com tais recursos, os governos podem formar coalizões políticas que alinhem overt policies (como anunciar a implantação das subprefeituras) e covert policies (como inserir subprefeituras na barganha com vereadores) (DAHL, 1989).

Portanto, deve-se "reconstruir as decisões importantes" adotadas pelos atores políticos nas "áreas em questão" para identificar quem inicia e produz as políticas, e quem tem poder de veto, para se conhecer os interesses em jogo. Conforme Dahl (1989, p. 126), há três tarefas inter-relacionadas para o governo formular e executar políticas: a) definir a direção da política com suas prioridades e investimento; b) desenvolver propostas e negociar acordos; c) implementá-las quando obteve acordo na negociação. Assim, em cada política governamental, pode-se analisar os atores que, com seus interesses e recursos políticos, opõem-se ou as apoiam.

É a política, com seus recursos de barganha, redução de conflito e construção de consenso, que organiza as relações entre os atores políticos. Por exemplo, controlar empregos públicos municipais é uma "arma política regular" e o mais importante uso político desse "ativo" é criar uma "flexível Câmara de Vereadores" (Board of Aldermen). Por isso, para Dahl (1989), o governo é um ator central para propor políticas, pois:

Toda a administração assume uma postura que fornece dicas aos participantes sobre quais tipos de políticas são mais prováveis de serem apoiadas ou não e quanto de recursos em energia, tempo, habilidade e dinheiro são prováveis de estarem disponíveis para diferentes políticas [...]. Se escolas são tratadas como uma área favorecida, ou contratos de trabalhos públicos [...], o tema é logo conhecido para todos aqueles que necessitam 
calcular o que é mais provável ou menos provável a fazer de acordo com seus próprios desejos e esperanças (DAHL, 1989, p. 126).

Quando o governo explicita seus objetivos, gera-se uma issue area que permite aos atores políticos adaptarem suas estratégias. O prefeito mobiliza apoio, mesmo de partidos oposicionistas, e costuma obter aquiescência sem sérios conflitos. Atendendo a tantos, o governo sabe dos limites das políticas que inicia ao defrontarse com as "pequenas soberanias" que são áreas controladas pelos atores políticos com seus interesses de poder (DAHL, 1989). Assim, para construir um padrão de coordenação e liderança política, o governo visa implantar uma "coalizão centrada no executivo". O prefeito é o ponto focal das negociações para integrar políticas e atores políticos por meio da barganha em torno de "interesses compartilhados". Para reduzir atritos internos na coalizão, o governo realiza indicações e constrói lealdades em áreas em que sua liderança é mais fraca (DAHL, 1989).

Segundo Mollenkopf (1994), em tais situações, importa analisar a "coalizão política dominante" que combina conhecer os atores políticos e as estratégias utilizadas pelo governo para conformar sua base de apoio. Esta, "para permanecer dominante, [...] deve ser capaz de administrar as tensões que inevitavelmente surgem das diferenças de interesse entre sua base eleitoral e seus aliados no governo" (MollenKOPF, 1994, p. 5). Embora "interesses contraditórios" denotem a diversidade de atores, com essa coalizão o governo divide seus oponentes e secundariza velhas clivagens políticas ao refazer as alianças em torno de uma centralidade de poder encabeçada pelo prefeito.

A coalizão dominante é uma aliança tática entre diferentes interesses que assegura a cooperação com outros centros de poder visando governar. Esse processo, com os recursos políticos que o governo possui, cimenta a unidade política entre diferentes grupos políticos. O sucesso da coalizão depende de sua capacidade em diluir conflitos, mediar interesses e, sobretudo, da liderança do prefeito. Portanto, o governo não apenas redistribui recursos entre vários atores políticos, mas acomoda seus interesses nem sempre coincidentes. Por isso, importa conhecer como se constitui esse arranjo político a partir das "regras do jogo" da competição na política local (MOLLENKOPF, 1994).

Entre os atores, está o "setor público produtor de interesses", que compreende, por exemplo, os executivos eleitos e/ou indicados para exercerem funções de governo e os partidos políticos. Estes últimos integram o governo e dele dependem para promoverem acomodações políticas. O governo também se vale da divisão de influência partidária nos territórios, como são as assembleias distritais (assembly districts), para articular diferentes interesses na coalizão política dominante (MOLlenKopf, 1994). 
Arranjos políticos podem favorecer tendências conservadoras na formação e atuação da coalizão dominante ao manter práticas institucionalizadas para distribuir empregos, contratos e outros benefícios. Se essa política é centralizada no gabinete do prefeito, ela revela escolhas visando se tornar dominante na política municipal. Ademais, o governo municipal e atores políticos como os vereadores ocupam espaços institucionais que condicionam a forma como ocorre a tomada de decisão política. Portanto, o lugar que atores políticos ocupam nas instituições é um elemento de barganha, sobretudo se sua posição é considerada estratégica para garantir apoios políticos continuados, como é o caso de vereadores nas câmaras municipais.

\section{O processo político e os seus limites institucionais}

"Arenas de poder" são estruturas institucionais que, com suas normas de funcionamento, condicionam decisões sobre políticas. Se poder também é a capacidade dos atores de participarem na produção das políticas de governo, é importante analisar as arenas que organizam institucionalmente esse processo. Conforme Lowi (1964), há três tipos de políticas públicas: distributivas, regulatórias e redistributivas. Para os fins deste artigo interessa apenas a primeira.

Políticas distributivas são específicas, desagregadas, desprovidas de normas gerais e têm no parlamento seu locus decisional. Como são decisões individualizadas, apenas por acumulação podem ser chamadas de políticas. Nesse modelo, perdedores e destinatários dos benefícios não entram em confronto direto e não há exclusões frente às sucessivas acomodações de interesses, pois todos recebem algo. "Patronagem" é o mais amplo sentido da palavra que pode ser tomada como sinônimo de "distributivo", visto que se multiplicam os interesses, o maior acesso dos atores políticos às ações de governo se torna inevitável e a redução do conflito cria uma "estrutura de poder" (LoWI, 1964, p. 693).

Essa estrutura de poder é formada por atores políticos sem compromissos comuns que não seja facilitar o próprio acesso aos benefícios públicos. $O$ governo atua como o "negociador" das concessões junto ao parlamento, que é o local privilegiado dessa política. Sobretudo nas cidades, "esta é a arena em que a máquina da dominação continua, se tal máquina estiver no controle em primeiro lugar" (LoWI, 1964, p. 713). Promove-se a política de cooptação antes que o compromisso, e, com essa política atendendo a muitos interesses, o governo visa desarticular a oposição e estabilizar as coalizões.

A abordagem de Lowi (1964) das arenas de poder e do papel do governo assemelha-se ao que Skocpol (2002, p. 21) chama de "visão tocquevilliana" do Estado: "sua configuração organizacional [...] afeta a cultura política, encoraja 
alguns tipos de formação de grupo e ações coletivas (mas não outras) e torna possível a ascensão de certas questões políticas (mas não outras)". A ação estatal e seu desenho institucional influenciam a atuação e os interesses de grupos, como os partidos políticos, ao mobilizar suporte às suas iniciativas.

Por exemplo, a patronagem governamental é um modo de ação política que pode permitir, via alocações distributivas, novos arranjos administrativos no interior do Estado que moldam o comportamento dos partidos políticos. Esta pode ser uma prática política institucionalizada quando os governos buscam constituir sua coalizão política dominante. Conforme Skocpol (2002, p. 25), "estruturas de administração pública e organizações de partidos políticos, consideradas em conjunto, percorrem um longo caminho para 'selecionar' os tipos de questões políticas que entrarão (ou serão mantidas fora) da 'agenda política' da sociedade", e, "onde grupos têm múltiplos, frequentemente conflitantes interesses, é necessário examinar o processo político em que particulares coalizões são formadas" (THELEN; STEINMO, 1992, p. 9).

Uma vez mobilizados os interesses de grupos políticos, esses tendem a manter suas demandas na mesma direção. O contorno passado de políticas e as decisões a elas vinculadas são mecanismos explicativos para analisar como os atores políticos atuam. Portanto, pode-se gerar uma combinação pouco virtuosa entre a persistência de práticas políticas institucionalizadas de patronagem com recursos públicos e os interesses de atores políticos que negociam seu apoio à "coalizão governamental" para manterem suas "pequenas soberanias". E se a politics historicamente apoia-se em normas que condicionam suporte às policies governamentais à barganha que conceda espaços de poder aos vereadores, torna-se mais difícil alterar essa rota. Portanto, na formação de alianças políticas:

Os aspectos do sistema político que agregam interesses, em particular o sistema de partidos e a legislatura, são centrais. Por canalizarem o modo como os grupos interagem em políticas e produzem políticas, essas instituições afetam enormemente as possibilidades para diversos grupos reconhecerem interesses comuns, construir alianças políticas e frequentemente determinam se tais alianças são necessárias (WEIR, 1992, p. 194).

Atores políticos podem realizar seu cálculo político conforme procedimentos institucionalizados de cooperação que presidem suas mútuas relações (LES GALÈs, 2010). Esse padrão de ação permite responder não só a questão quem governa, à la Dahl, mas também como se governa. Implantar novos formatos administrativos, como são as subprefeituras, exemplifica esse tipo de problema político. Novos modelos organizacionais podem gerar confronto com atores políticos apegados aos seus interesses, segundo os modelos de regulação política institucionalizados. Com 
efeito, "políticas, uma vez adotadas, inserem-se nas instituições. Elas são associadas com regras, expectativas e compromissos. Ao afetar a atenção e as aspirações, elas afetam o comportamento dos interesses futuros dos participantes políticos" (MARCH; OLSEN, 1984, p. 745).

\section{O caso de São Paulo: política de alianças e as subprefeituras na partilha do poder $^{5}$}

Como um eixo estratégico do programa de governo, a descentralização inseriuse na agenda da gestão Marta Suplicy desde o seu início, apesar das dificuldades para se obter um acordo sobre o modelo de subprefeituras a ser implantado. Em setembro de 2001, o governo apresentou à Câmara de Vereadores um projeto de lei propondo a criação de 31 subprefeituras. Até esse momento, inexistia uma concepção administrativa para as subprefeituras, tanto que, pelos artigos 16 a 19 do projeto, o Executivo ficava autorizado a criar, por meio de decretos, unidades gerenciais para atender as demandas locais.

O governo não quis explicitar a magnitude da descentralização para a Câmara Municipal, pois, em 2001, sua base parlamentar era minoritária. Já os vereadores tinham interesse em manter sua influência nos territórios. Essa situação congelou o debate no parlamento, pois os vereadores temiam não mais poder indicar afilhados para cargos locais. Muitos parlamentares recordavam da gestão Erundina, quando as ARs foram distribuídas somente entre os diretórios zonais do PT (TEIXEIRA, 2004).

A dificuldade de o governo construir uma maioria parlamentar, associada ao receio de perder a votação e não conseguir implantar as subprefeituras, como ocorrera na gestão Erundina, adiou a tramitação da matéria. Os vereadores sabiam que o governo teria que negociar para obter os votos favoráveis ao projeto. A esse contexto somou-se a disputa por influência nas regiões entre vereadores da base governista, e o medo de que as subprefeituras estimulassem o surgimento de líderes regionais que diminuíssem o poder dos parlamentares. O projeto de lei foi apresentado em setembro de 2001 e aprovado em julho de 2002, sobretudo pela ausência de acordo na coalizão governista.

Coma aprovação da Leino13.399, foram criadas31 subprefeituras regulamentando o artigo 77 de Lei Orgânica Municipal (LOM). As subprefeituras passaram a ter poder formal de decisão, planejamento, investimento e autonomia administrativa. A mesma lei regulamentou outros artigos da LOM: igualou subprefeitos e secretários como auxiliares diretos do prefeito; definiu as subprefeituras como representantes locais da administração municipal e as transformou em unidades orçamentárias.

\footnotetext{
${ }^{5}$ A discussão sobre o caso de São Paulo baseia-se em Grin (2015).
} 
O subprefeito, como representante político local do governo, teria mais poder decisório do que os administradores regionais que respondiam apenas por serviços de manutenção urbana (SANTOS; BARRETTA, 2004). Isso porque se definiu a organização das subprefeituras com sete coordenadorias (artigo 12 da Lei no 13399): Ação Social e Desenvolvimento; Planejamento e Desenvolvimento Urbano; Manutenção e Infraestrutura Urbana; Projetos e Obras Novas; Educação; Saúde; e Administração e Finanças. Menos do que analisar o desenho administrativo aprovado, para este artigo importa destacar que a organização das subprefeituras ampliou os recursos financeiros e cargos a serem preenchidos localmente.

A formalização das subprefeituras produziu uma "afinidade eletiva" com a importância vital que o governo atribuía à construção de uma maioria parlamentar, visando evitar o isolamento sofrido pela gestão Erundina. No início, o Governo Marta Suplicy tinha uma bancada de 19 vereadores (16 do PT e 3 do PCdoB), apenas um a mais do que dispunha a gestão Erundina, e se previam dificuldades similares para forjar uma maioria parlamentar. Havia ainda dois vereadores do PSB, em tese aliado do governo, mas pouco obedientes às definições partidárias (MARTINS, 2001).

Desde o início de 2002, segundo ano da gestão, dada a dificuldade de aprovar seus projetos no parlamento, o Executivo ampliou sua base aliada com o discurso de um "governo amplo". Até abril desse ano, o governo tinha conseguido o apoio da bancada do PMDB (seis vereadores) e da bancada do PL (três vereadores) com negociações que envolviam cargos nas ARs. Com o PSB, a base governista de 30 parlamentares se tornou majoritária (a Câmara tem 55 parlamentares). Mas o governo planejava ampliar essa coalizão, para o que a criação das subprefeituras foi o estímulo necessário para obter apoio oferecendo cargos locais.

O eufemismo do "governo amplo" tinha uma dupla face que envolvia a tramitação do projeto das subprefeituras. A overt policy reiterava a necessidade de renovar a gestão local em bases democráticas e mais próximas do cidadão. Esse discurso político alimentava a visão do PT como partido alinhado à revisão da relação centralizadora entre o Estado local e a sociedade. A covert politics evitava mostrar os acordos e concessões para os vereadores, pois isso tornaria público o que era visto pela base social de apoio do PT como expressão de fisiologismo levado ao seu paroxismo pelo malufismo até o ano 2000.

Assim, se a descentralização foi proposta como medida de caráter redistributivo, a construção da coalizão política dominante apoiou-se em políticas distributivas. Não que constituir políticas de alianças seja secundário, mas a forma como esse processo se deu em São Paulo expôs as incoerências do projeto petista em favor de uma gestão mais democrática da cidade. O governo seguiu atuando conforme as regras do jogo da política municipal que mantinha as "pequenas soberanias" nos bairros. A 
ação governamental seguiu conformando o comportamento dos vereadores a partir de sua configuração organizacional (a novidade das subprefeituras exponenciou as práticas políticas tradicionais) e das suas prioridades (combinar a descentralização da gestão municipal com a formação de sua coalizão política dominante).

Os vereadores da coalizão dominante temiam perder influência em seus redutos eleitorais, pois a nomeação dos subprefeitos pelo Executivo poderia fortalecer as lideranças de bairro. A opção do governo foi franquear a indicação dos subprefeitos aos vereadores. Assim, ao aprovar as subprefeituras, o governo fez desse processo um marco para consolidar sua política de alianças no parlamento a partir de julho de 2002. Todavia, o governo evidenciou que a democracia participativa não teria prioridade na gestão local, mas sim a divisão de poder com os vereadores. Conforme Félix Sanchez (2006), Coordenador do Orçamento Participativo:

Como fazer para governar de forma efetivamente democrática? [...]. A ideia das Subprefeituras tinha suas limitações, pois não houve a implementação dos conselhos de representantes como expressão do direito à participação [...] o que, a bem da verdade, também, era um elemento de conflito entre nós. Provavelmente, a ampla coalizão de partidos e parlamentares que sustentava o governo Marta Suplicy não tolerasse essa convivência. Como faríamos, então, para governar com ela: ouvindo a população ou o vereador do bairro ou do distrito (SANCHEZ, 2006, p. 55)?

Essa estratégia foi expressa por Antônio Donato (2006), Secretário Municipal das Subprefeituras em 2003:

[...][D]o ponto de vista do processo político, depois da Constituição de 1988, o país vive o chamado presidencialismo de coalizão: tem-se o parlamento forte, com uma multiplicidade de partidos, o que impõe a necessidade de construir alianças para governar, pois a minoria no parlamento significa um grave problema de governabilidade. A aprovação da lei das Subprefeituras passou por essa discussão, inclusive resultando na participação de partidos aliados na administração das Subprefeituras. Podemos dizer que o governo Marta arquitetou uma maioria parlamentar e o terreno prioritário dos acordos foi o das Subprefeituras (DonATO, 2006, p. 41-42).

Essa forma de partilhar o poder com os vereadores nas subprefeituras se materializou no início de 2003. A construção da coalizão política dominante não pode ser dissociada da magnitude da descentralização quanto à transferência de serviços e servidores para as regiões. Menos de um ano após a aprovação da lei, as subprefeituras administravam $70 \%$ do total de servidores municipais. Em termos financeiros, o montante de recursos transferidos às regiões cresceu quase seis vezes 
(de R\$ 550 milhões em 2003 para quase R\$ 3 bilhões em 2004), o que representava 20,9\% do orçamento municipal (PREFEITURA MuniCIPAL de SÃo PAUlo, 2004).

Quanto à estrutura administrativa, pela Lei no 13.682/2003, definiram-se 14 cargos de livre nomeação em cada subprefeitura: o subprefeito, o chefe de gabinete, cinco assessorias (jurídica, técnica, comunicação, defesa civil e praça de atendimento) e sete coordenadores. Havia ainda 47 cargos de chefia, geralmente ocupados por servidores municipais. As 31 subprefeituras possuíam 1.971 postos diretivos (434 cargos de livre nomeação e 1537 funções de chefia). Como a definição final de como manejar esses recursos era controlada pela Prefeita, ponto fulcral da coalizão centrada no executivo, isso Ihe dava um poder de barganha significativo junto aos vereadores.

A amplitude da descentralização, o tamanho dos recursos orçamentários e a quantidade de cargos a serem nomeados localmente exponenciaram a política historicamente vigente no município de dividir a gestão dos territórios com os vereadores. $O$ desenho administrativo e financeiro das subprefeituras constituiu os fundamentos para manter e ampliar a lógica da vereança nos territórios. Em linha com Dahl (1989), essas foram as armas políticas regulares para "flexibilizar" os vereadores.

O Quadro 1 (GRIN, 2015) mostra como as subprefeituras serviram para ampliar a coalizão de governo, quando comparadas com a divisão política das ARs, que, até o final de 2002, retratava basicamente a coalizão eleitoral entre o PT e o PCdoB. Vê-se que o PT se manteve como o partido majoritário, com $74 \%$ das 31 subprefeituras (23 regiões), enquanto as outras oito se dividiram entre sete partidos da coalizão de governo. Nos cargos de segundo escalão, com os dados que foi possível coletar, ao menos em 16 locais, outros partidos, além da coalizão eleitoral, realizaram indicações.

Esse processo ocorreu em 52\% das subprefeituras, sem que o PT deixasse de ser majoritário, pois a participação dos aliados direcionou-se mais para o segundo escalão (cargos de coordenação e supervisão). Estes costumavam ter um perfil mais de "bairro" ao serem indicados pelos vereadores. Assim, o "modelo político" prevalecente nas subprefeituras caracterizou-se por: a) não entregar apenas para um partido ou vereador, mesmo que fosse do PT; b) manter a hegemonia e a direção política do PT na maioria das regiões; c) organizar a participação de aliados em um número menor de locais e em cargos de segundo escalão com menos peso político (GRIN, 2015).

Contudo, essa política da partilha de poder nas regiões era de difícil solução: franqueava aos vereadores indicarem os subprefeitos, mas tentava impedir que os territórios se tornassem seus feudos. A opção de governar as regiões com os vereadores foi alvo de críticas de um de seus articuladores à época, o Secretário de Governo em 2004. 
Quadro 1 - Indicações nas ARs (2001/2002) e nas subprefeituras (2003/2004)

\begin{tabular}{|c|c|c|c|}
\hline \multicolumn{2}{|c|}{$\begin{array}{l}\text { Administrações regionais } \\
\text { Aliança eleitoral no período } 2001 / 2002\end{array}$} & \multicolumn{2}{|c|}{$\begin{array}{l}\text { Subprefeituras } \\
\text { Aliança de governo no período } 2003 / 2004\end{array}$} \\
\hline Territórios & Indicação do AR & Indicação do subprefeito & Outros cargos \\
\hline Aricanduva & Não obtida & Celso Jatene (PTB) & Antônio Rodrigues (PL) \\
\hline Butantã & Sem partido & $\begin{array}{l}\text { Ex-Secretário da } \\
\text { subprefeituras Antônio }\end{array}$ & $\begin{array}{l}\text { Sec. Subprefeituras Carlos } \\
\text { Zaratini (PT) }\end{array}$ \\
\hline Campo Limpo & PT & Donato (PT) & Dep. Vicente Cândido (PT) \\
\hline Casa Verde & PT & Antônio Rodrigues (PL) & Eliseu Gabriel (PSB) \\
\hline Capela do Socorro & PT & $\begin{array}{l}\text { Rubens Calvo (PT) } \\
\text { ArselinoTatto (PT) }\end{array}$ & $\begin{array}{l}\text { Edivaldo Estima (PPB), } \\
\text { Milton Leite (PMDB), } \\
\text { Antônio Goulart (PMDB), } \\
\text { Não obtidas }\end{array}$ \\
\hline Cidade Tiradentes & Criada em 2002 & $\begin{array}{l}\text { Dep. Est. Italo Cardoso (PT) } \\
\text { Claudete Alves (PT)/Dep. }\end{array}$ & Paulo Frange (PTB) \\
\hline Ermelino Matarazzo & PCdoB & $\begin{array}{l}\text { Fed. Arlindo Chinaglia (PT) } \\
\text { Dep. Ana Martins (PCdoB)/ }\end{array}$ & $\begin{array}{l}\text { Dep. Devanir Ribeiro (PT)/ } \\
\text { Alcides Amazonas (PCdoB) }\end{array}$ \\
\hline Freguesia do Ó & PT & Viviani Ferraz (PL)/Baratão & José Américo (PT) \\
\hline Guaianases & PT & (PDT) & José Ferreira (Zelão) (PT) \\
\hline Ipiranga & PT & Beto Custódio (PT) & Jooji Hato (PMDB) \\
\hline Itaim Paulista & PT & Dep. Fed. José Mentor (PT) & Não obtidas \\
\hline Itaquera & PCdoB & João Antônio (PT) & Adriano Diogo (PT) \\
\hline Jabaquara & PCdoB & Toninho Paiva (PL) & Roger Lin (PSB) \\
\hline Lapa & PT & Francisco Chagas (PT) & Paulo Frange (PTB) \\
\hline M'Boi Mirim & Criada em 2002 & $\begin{array}{l}\text { Augusto Campos (PT) } \\
\text { Lucila Pizani (PT) }\end{array}$ & $\begin{array}{l}\text { Milton Leite (PMDB)/Dep. } \\
\text { Vicente Cândido (PT) }\end{array}$ \\
\hline Mooca & PT & & Myriam Athiê (PMDB) \\
\hline Parelheiros & Criada em 2002 & Adriano Diogo (PT) & Não obtidas \\
\hline Penha & PT & Edivaldo Estima (PPB) & Toninho Campanha (PDT) \\
\hline Perus & PT & João Antônio (PT) & Eliseu Gabriel (PSB) \\
\hline Pinheiros & PT & Raul Cortez (PPS) & Não obtidas \\
\hline Pirituba & PT & Indicação do Executivo & Eliseu Gabriel (PSB) \\
\hline Santana & PT & $\begin{array}{l}\text { José Laurindo (PT) } \\
\text { Carlos Apolinário (PDT) }\end{array}$ & $\begin{array}{l}\text { Celso Cardoso (PFL)/ } \\
\text { Humberto Martins (PMDB)/ } \\
\text { José Olímpio (PMDB) }\end{array}$ \\
\hline Santo Amaro & PT & & Dep. Est. Italo Cardoso (PT) \\
\hline São Mateus & PT & Antônio Goulart (PMDB) & Dep. Devanir Ribeiro (PT) \\
\hline S. Miguel Paulista & PT & $\begin{array}{l}\text { Francisco Chagas (PT) } \\
\text { Paulo Teixeira (Sec. }\end{array}$ & $\begin{array}{l}\text { Paulo Frange (PTB)/João } \\
\text { Antônio (PT) }\end{array}$ \\
\hline Sé & PT & Municipal de Habitação) & Não obtidas \\
\hline Tremembé/Jaçanã & PT & Indicação do executivo & Carlos Apolinário (PDT) \\
\hline Vila Prudente & PT & Dep. José Mentor (PT) & Francisco Chagas (PT) \\
\hline Vila Maria & Sem partido & $\begin{array}{l}\text { Flávia Pereira (PT) } \\
\text { Wadih Mutran (PPB) }\end{array}$ & $\begin{array}{l}\text { Arselino Tatto (PT)/Manoel } \\
\text { Cruz (PRONA) }\end{array}$ \\
\hline Vila Mariana & PT & José Américo (PT) & Antônio Rodrigues (PL) \\
\hline
\end{tabular}

Fonte: Grin (2015). Organizado com base em matérias jornalísticas (Estado de São Paulo de 30/06/2004 e Folha de São Paulo de 29/12/2000), complementado pelas entrevistas realizadas com os subprefeitos das Subprefeituras de Capela do Socorro e Freguesia do Ó. No período 2003-2004 as indicações foram oriundas de vereadores e de deputados, que eram ex-vereadores eleitos em 2000 pertencentes aos partidos da base aliada, e que mantiveram influência política nas regiões. 
Para Tatto (2006), o governo errou ao organizar sua coalizão de apoio, o que se refletiu nas regiões: a) como efeito da construção da coalizão parlamentar, as indicações aceitas na cúpula do PT e dos partidos aliados não foram assimiladas nas bases partidárias regionais, sobretudo no caso de antigos adversários políticos; b) compor a maioria parlamentar gerou conflitos em bairros em que nomeação do subprefeito desagradou as lideranças locais.

O governo não conseguiu administrar os distintos interesses regionais, especialmente a convivência de grupos políticos às vezes adversários. Equilibrar a política de cooptação e os compromissos do programa de governo gradativamente fez a balança pender para seu viés distributivo. Como o novo modelo organizacional das subprefeituras podia gerar conflitos com os vereadores apegados aos seus interesses, o governo mostrou-se pouco disposto a alterar os padrões vigentes de regulação política e de cooperação institucionalizados junto ao parlamento. Desse modo, as subprefeituras constituíram-se virtualmente em um parlamento estendido, pois decisões adotadas nas regiões impactavam a possibilidade de os vereadores apoiarem o governo, bem como esses condicionavam seus votos em favor do Executivo ao atendimento de suas demandas por serviços e indicações de aliados nos bairros.

A criação das subprefeituras manteve uma velha prática (partilhar os territórios entre vereadores) com fins idênticos (consolidar a base de apoio governamental no parlamento). Sob esse ponto de vista, a implantação das subprefeituras materializou o caráter relacional entre instituições políticas, dependentes de sua trajetória histórica, e os interesses dos atores políticos. Ao mesmo tempo, dada a relevância das subprefeituras no programa de governo, ficou claro para os vereadores que essa era uma issue area que conformou no seu entorno uma rede de atores políticos que alimentou "estranhas coalizões como nunca houve". Nesse caso, a aliança do PT com os vereadores chamados tradicionais por suas práticas políticas do "toma lá da cá".

A descentralização organizada por meio das subprefeituras impactou o jogo da política municipal, pois conforme Borja (1984), a divisão de poderes nas regiões refletiu o peso político que os vereadores detinham nos bairros. Esses recursos políticos (influência local) foram utilizados na barganha realizada com o governo quando assumiu centralidade a construção da sua coalizão política dominante. Com efeito, a transferência de recursos financeiros, serviços e servidores para as regiões, que deveria ser a base de uma nova governabilidade urbana, transformouse no principal incentivo para os vereadores ampliarem ainda mais sua histórica influência e poder nos bairros. 


\section{O caso de Rio de Janeiro: gestão e política no manejo das subprefeituras ${ }^{6}$}

Em 1993, a criação de subprefeituras no Município do Rio de Janeiro era coerente com as medidas estabelecidas pela Constituição de 1988, propensas a descentralizar as estruturas político-administrativas do Estado brasileiro e a democratizar o processo decisório de produção de políticas públicas (ABRUcıo; Couto, 1996; Kulgemas; SolA, 1999). Pelos propósitos de que estariam incumbidas, as subprefeituras figurariam como um mecanismo de governança local, com potencial para incrementar a capacidade institucional de ação estatal, especificamente, a de coordenação e implementação de políticas e serviços públicos e, ainda, de interlocução com a sociedade (FRISCHTAK, 1994). Nessa concepção, as subprefeituras funcionariam como instrumentos de gestão da cidade, circunscritas a áreas geográficas específicas, com as competências gerais de identificar as demandas da população e informar aos órgãos da prefeitura as prioridades da região, coordenando e dirigindo a prestação local dos serviços públicos.

$\mathrm{Na}$ prática, no entanto, a forma como as subprefeituras cariocas foram criadas e organizadas limitaria o seu potencial como um instrumento de gestão descentralizada no âmbito local. Concretamente, é mais razoável concebê-las como oriundas de uma desconcentração administrativa do governo local. Isso significa que as subprefeituras surgem para cumprir funções atribuídas pelo prefeito, a quem estão direta e hierarquicamente subordinadas como parte do Executivo municipal. Em sentido estrito, a desconcentração diz respeito a um fenômeno em que ocorre transferência e/ou distribuição de competências decisórias internamente, isto é, no âmbito da administração pública, em que os órgãos e agentes ligam-se por um vínculo de hierarquia ao chefe do governo7, a quem cabe definir o nível de discricionariedade dos entes subordinados em relação ao exercício das funções delegadas.

Sob esse arranjo administrativo desconcentrado, as subprefeituras são, a rigor, desprovidas de autonomia e autoridade decisória para a realização de suas atribuições, a menos que o chefe do governo estabeleça de outro modo (formal

\footnotetext{
${ }^{6}$ O caso do Rio de Janeiro baseia-se em Lameirão (2007).

${ }^{7}$ Segundo os termos de Celso de Mello, "descentralização e desconcentração são conceitos claramente distintos. A descentralização pressupõe figuras jurídicas diversas: aquele que originalmente tem ou teria titulação sobre certa atividade e aquela(s) outra(s) às quais foi atribuído o desempenho das atividades em causa. A desconcentração está sempre referida a uma só pessoa, pois cogita-se da distribuição de competências na intimidade delas, mantendo-se, pois, o liame unificador da hierarquia. Pela descentralização rompe-se uma unidade personalizada e não há vínculo hierárquico entre a administração central e a pessoa estatal descentralizada. Assim, a segunda não é 'subordinada' à primeira. O que passa a existir na relação entre ambas, é um poder chamado controle" (Mello, 2008, p. 151).
} 
ou informalmente). No caso do Rio de Janeiro, o prefeito tem total controle sobre a estrutura das subprefeituras, podendo inclusive extingui-las. Ao longo do tempo e de diferentes governos, coube aos prefeitos decidir o número de subprefeituras, suas funções e competências, a localidade em que seriam estabelecidas, bem como o tipo de relação com os demais órgãos da prefeitura.

Dessa maneira, qualquer alteração na organização das subprefeituras - como definição da área de abrangência, criação ou extinção - realiza-se mediante a edição de decretos. Essas decisões são estabelecidas unilateralmente pelo prefeito, prescindindo da aquiescência da Câmara dos Vereadores. A flexibilidade desse arranjo pode ser exemplificada pela variação do número de subprefeituras no decorrer do tempo.

Comparativamente, houve intensa oscilação no total que cada prefeito manteve em suas respectivas gestões. Em 1993, Cesar Maia criou cinco, e no fim do seu primeiro mandato já contava com oito. Na gestão de Conde, o município chegou a contar com 15. Nos dois mandatos seguintes de Maia, esse número diminui inicialmente, para um total de dez, mas logo expandiu-se, chegando a 198. Em 2009, quando assume a prefeitura, Paes reduz o quantitativo de 19 para 69 , mas em 2015 são criadas mais duas, ampliando o seu total para $8^{10}$.

A gestão do arranjo das subprefeituras cariocas é, então, comandada pelo prefeito. Contudo, pode-se dizer que esse comando foi mais proeminente em um momento específico, no primeiro mandato de Cesar Maia (1993-1996), quando as subprefeituras foram criadas. Coube a Maia definir quantas subprefeituras seriam estabelecidas, quem iria dirigi-las e de que modo deveriam funcionar. A centralidade dessas decisões explica-se pelas características do processo de criação dessas agências locais e, ainda, por algumas condições políticas estrategicamente exploradas pelo então prefeito para maximizar seu nível de discricionariedade no exercício do governo local. Uma dessas condições tem a ver com o fato de ter ganho

\footnotetext{
${ }^{8}$ Conforme o decreto no 25.213 de 05/04/2005.

${ }_{9}$ Ao longo da campanha eleitoral de 2008 para a prefeitura carioca, a imprensa noticia várias críticas de Eduardo Paes sobre o tratamento dado às subprefeituras nos últimos governos de Cesar Maia. Nas palavras de Paes, considerando o papel das subprefeituras no contexto anterior à sua posse no Executivo carioca, “[...] no passado, o prefeito [Cesar Maia] deu força a elas. Agora, ele as esvazia. O número de subprefeitos é alto e eles não fazem parte do primeiro escalão. Deveremos reduzir esse número, para fortalecer as subprefeituras - explicou, dizendo que a principal característica dos subprefeitos deve ser a competência". (Disponível em http://www.agenciario. com.br/materia.asp?cod=51020\&codEdit=3\#.Ve86ARFViko).

${ }^{10}$ Desde o primeiro ano do Governo Paes, em 2009, existem as seguintes subprefeituras, sob a denominação de coordenadorias especiais de áreas de planejamento: Barra e Jacarepaguá, Centro, Zona Sul, Zona Oeste, Grande Tijuca e Zona Norte. Em 2015 foram criadas as subprefeituras Zona Norte 2 e Ilha do Governador.
} 
as eleições para prefeitura, em 1992, inesperadamente ${ }^{11}$ e de forma relativamente independente, do ponto de vista político-partidário.

Segundo Francisco Marques (2003), desde a campanha eleitoral, Maia já pretendia construir seu próprio grupo político, independente das esferas partidárias tradicionais. Para tanto, o prefeito empregou uma estratégia que combinava duas frentes: (i) o estabelecimento de um núcleo de governo "técnico", composto por quadros sem laços prévios com partidos - que ocupariam os cargos de secretários; e (ii) a concessão de prerrogativas de poderes, na esfera administrativa municipal, aos agentes responsáveis pela gestão regionalizada da cidade - os subprefeitos, em sua enorme maioria quadros estreantes. Assim, com o objetivo de formar seu grupo, Maia atribuiu a jovens colaboradores a gestão das subprefeituras ${ }^{12}$, cuja principal atribuição seria representar regionalmente a prefeitura, recolhendo junto à população as demandas do dia a dia e providenciando seu atendimento.

Nesse arranjo, não caberia às subprefeituras executar o atendimento às demandas que recebiam da população. Isso continuaria a cargo das secretarias e seus respectivos órgãos de operação regionalizados. A novidade consistiria em que as subprefeituras, sob a delegação direta do então prefeito, teriam a competência de ordenar aos órgãos da administração pública municipal a execução de serviços públicos.

O propósito de Cesar Maia de criar um grupo político por meio das subprefeituras foi, por fim, exitoso. Na eleição ocorrida em 1996, quatro subprefeitos (Eduardo Paes, Alexandre Cerruti, Índio da $\operatorname{Costa}^{13}$ e Paulo Cerri) se elegeram vereadores do Rio de Janeiro, pela mesma sigla partidária do prefeito, na época, o PFL. Eduardo Paes, subprefeito da Barra da Tijuca e Jacarepaguá, foi o candidato mais votado na eleição para a Câmara Municipal, enquanto Alexandre Cerruti, subprefeito da Zona Norte,

\footnotetext{
${ }^{11}$ No curso do processo eleitoral para a Prefeitura do Rio de Janeiro em 1992, a eleição de Cesar Maia era tida como um resultado inesperado por quadros políticos da cidade e até mesmo por seu partido, na época o PMDB. Cesar Maia foi eleito em 20 turno, com $51,8 \%$ dos votos.

${ }^{12}$ Sustentando sua intenção em formar um grupo político por meio das subprefeituras, o Prefeito Cesar Maia declara que "[...] no primeiro governo, através principalmente das subprefeituras, fui construindo um grupo de renovação de jovens [...]. Na campanha eleitoral, eu decidi dar a eles posição de destaque e se eles mostrassem iniciativa e ousadia, eu os levaria, como os levei, a posição de destaque na administração, mesmo sem experiência anterior. Eles tinham capacidade e não tinham formação, que somada à capacidade, gerou sinergia" (MARQUES, 2003, p. 36).

${ }^{13}$ Índio da Costa dirigia a V Região Administrativa (Copacabana), mas recebia atenção especial do Executivo, usufruindo do mesmo status atribuído aos subprefeitos.
} 
foi o quarto. Os subprefeitos eleitos obtiveram sua maior porcentagem de votos nas regiões que compunham a área de abrangência de suas respectivas subprefeituras ${ }^{14}$.

O encerramento do primeiro Governo Maia representou, no entanto, um novo período na gestão das subprefeituras. Ao transmitir o comando da cidade ao seu sucessor, Luiz Paulo Conde (1997-2000), Maia legaria um complexo quadro político, relativo às pressões de alguns vereadores para assumir o controle sobre as subprefeituras. Isso porque, ao distribuir seus colaboradores pela cidade, entre 1993 e 1996, o então prefeito ocasionou impactos em dinâmicas políticas que se processavam em nível local, por meio das quais muitos vereadores obtinham seus votos e se elegiam para cargos públicos.

O estabelecimento das subprefeituras sobrepôs-se a um longínquo esquema de atuação em que cabia aos políticos "do bairro", ou comunitários, a articulação com os órgãos públicos a fim de providenciar a prestação de serviços na localidade em que concentravam sua base eleitoral ${ }^{15}$. No decorrer do primeiro mandato de Maia, com os subprefeitos passando a desempenhar essa mesma função na área desses políticos, criou-se um contexto de acirrada competição entre os dois grupos ${ }^{16}$.

A partir de 1997, a expansão do número de subprefeituras e a concessão a alguns vereadores da prerrogativa de indicar os novos subprefeitos conformaram a estratégia delineada pelo Governo Conde a fim de solucionar o impasse político. Essas medidas contrastavam com o contexto vigente no primeiro governo Maia, quando o controle sobre as subprefeituras, tanto de quem as comandaria como da função específica que exerceria, foi de sua exclusiva prerrogativa. É possível dizer que o próprio poder das subprefeituras nos anos iniciais de sua existência foi afiançado por Cesar Maia. Assim, teria sido a delegação de autoridade do então prefeito, no primeiro mandato, aos subprefeitos o que lhes garantiu o poder de ordenar aos órgãos administrativos competentes a execução das demandas e, em

\footnotetext{
${ }^{14}$ Especificamente, Eduardo Paes (subprefeito da Barra da Tijuca e Jacarepaguá) obteve $53 \%$ da sua votação nas zonas eleitorais da Barra e de Jacarepaguá; Alexandre Cerruti (subprefeito da Zona Norte) recebeu 64,61\% dos seus votos em zonas de Madureira e adjacências; Índio da Costa (administrador regional de Copacabana) teve 70,6\% dos votos na Zona Sul; e Paulo Cerri (subprefeito da Tijuca e Adjacências) recebeu 71,43\% de votação em zonas eleitorais da Tijuca e adjacências.

${ }^{15}$ Ver Diniz (1982) e Kuschnir (2000).

${ }^{16}$ Segundo uma vereadora, Cesar Maia seguiu numa estratégia injusta, no seu primeiro governo, ao conceder muito espaço aos subprefeitos em detrimento dos vereadores. Afirma a política que "[o prefeito] queria fazer essas pessoas. Então, ele passou a dar cargos, prestígio, enfim, proteger e abrir espaço na mídia. [Por isso] eu e alguns vereadores tivemos algumas dificuldades no primeiro governo devido a ele querer investir só nessa turma, que a gente chamava 'os que eram criados pelo prefeito'. Eles não tinham um passado de trabalho, não tinham lutado por nada. Foi dado a eles tudo nas mãos" (MARQUES, 2003, p. 40).
} 
decorrência disso, de projetar as subprefeituras como um canal célere de prestação de serviço público.

Sob as circunstâncias presentes no Governo Conde, sobretudo com a ampliação do número de subprefeituras e a concessão aos vereadores aliados da prerrogativa de indicar alguns dos novos subprefeitos, passariam a coexistir ao nível das subprefeituras dois tipos de orientações, uma proveniente do governo e outra que emanaria das diretrizes do político local. A partir desse período, parece não haver mais as condições para o então chefe do Executivo manter o funcionamento das subprefeituras nos moldes definidos no primeiro mandato de Maia.

Quando retorna à prefeitura, em 2001, para exercer seu segundo mandato, Cesar Maia, embora diminua o número de subprefeituras deixado por Conde ${ }^{17}$, volta, com o tempo, a ampliá-lo. Segundo o próprio prefeito, a decisão de prosseguir com a abertura iniciada por Conde era inevitável, devido às articulações políticas que já estavam formadas em torno das subprefeituras. Considerando as iniciativas do seu antecessor como causa determinante da sua nova estratégia, Cesar Maia expõe sua posição em relação às subprefeituras em seu segundo e terceiro mandato:

O Conde concedeu muito. Quando retornei, vi uma situação difícil de inverter. Eu tinha que fazer algum tipo de concessão também. Procurei fazer concessões no 2 e e 3 governo mais ao nível das RAs, e minimizar a concessão ao nível das subprefeituras. Mas as subprefeituras que tenho hoje, eu tive que ampliar [...] para poder, de um lado, abrir espaço para as demandas dos vereadores sem desmontar o sistema, [por]que eu preciso ter no mínimo 60 ou $65 \%$ das subprefeituras operando esse tipo de política [empreendido durante o primeiro governo]. Com isso, tive que fazer algumas concessões, criando novas subprefeituras, e isso perde um pouco a unidade de seu propósito ${ }^{18}$.

Em termos empíricos, observa-se que o desmembramento ${ }^{19}$ das subprefeituras remonta à gestão do Prefeito Conde, mas foi intensificado nos dois últimos mandatos de Maia, que, inclusive, introduziu algumas novidades, tais como: subprefeituras sem ligação com região administrativa, e expressiva quantidade de subprefeituras que se ligam a apenas uma RA. Retratando a situação vigente durante o último mandato de Cesar Maia, o Quadro 2 mostra como variava a quantidade de RAs sob o escopo de cada subprefeitura.

\footnotetext{
${ }^{17}$ Decreto no 19.402 de 01/01/2001.

${ }^{18}$ Entrevista à autora, Rio de Janeiro, 20/02/2006.

${ }^{19}$ Entende-se a ampliação do número de subprefeituras como resultado de um processo de desmembramento, pois novas subprefeituras surgem a partir do fracionamento daquelas estabelecidas originalmente.
} 
Quadro 2 - Área de abrangência das subprefeituras do Rio de Janeiro, por RA (2007)

\begin{tabular}{|c|c|c|}
\hline $\begin{array}{l}\text { Áreas de } \\
\text { planejamento }\end{array}$ & Subprefeituras & Regiões administrativas \\
\hline \multirow{4}{*}{ AP - 1} & Centro Histórico & II - Centro \\
\hline & Centro & I - Portuária; VII - São Cristóvão \\
\hline & Tijuca e Adjacências & III - Rio Comprido; XXIII - Santa Teresa \\
\hline & - & XXI - Paquetá \\
\hline \multirow{4}{*}{ AP - 2} & Zona Sul & V-Copacabana; VI - Lagoa; XXVII - Rocinha \\
\hline & Zona Sul II & IV - Botafogo \\
\hline & Tijuca e Adjacências & VIII - Tijuca \\
\hline & Vila Isabel e Grajaú & IX - Vila Isabel \\
\hline \multirow{9}{*}{ AP - 3} & Leopoldina Norte & $X$-Ramos \\
\hline & Leopoldina Sul & XXX - Maré; XXXI - Vigário Geral \\
\hline & Grande Irajá & XI - Penha; XIV - Irajá \\
\hline & Grande Méier & XII - Inhaúma; XIII - Méier \\
\hline & Zona Norte & $\begin{array}{l}\text { XV - Madureira; XXII - Anchieta; XXV - } \\
\text { Pavuna }\end{array}$ \\
\hline & Ilha do Governador & XX - Ilha do Governador \\
\hline & Vila Isabel e Grajaú & XXVIII - Jacarezinho \\
\hline & Lins de Vasconcelos & - \\
\hline & - & XXIX - Complexo do Alemão \\
\hline \multirow{2}{*}{$A P-4$} & Barra da Tijuca & XXIV - Barra da Tijuca \\
\hline & Jacarepaguá & XVI - Jacarepaguá; XXXIV - Cidade de Deus \\
\hline \multirow{4}{*}{ AP - 5} & Zona Oeste & XVIII - Campo Grande \\
\hline & $\begin{array}{l}\text { Sta. Cruz e Pedra de } \\
\text { Guaratiba }\end{array}$ & XIX - Santa Cruz; XXVI - Guaratiba \\
\hline & Bangu & XVII - Bangu; XXXIII - Realengo \\
\hline & Vila Militar & - \\
\hline
\end{tabular}

Fonte: Decreto municipal № 25.053 de 03/02/2005.

Notam-se subprefeituras que atuavam apenas com uma RA, enquanto outras coordenavam duas ou três. Percebe-se, ainda, que RAs (XXI-Paquetá e XXIXComplexo do Alemão) não se ligavam à subprefeitura alguma, pois responderiam diretamente à Secretaria Municipal de Governo. Por outro lado, algumas subprefeituras (Lins de Vasconcelos e Vila Militar) não mantinham ligação com quaisquer regiões administrativas.

Certamente, quanto menos RAs estivessem sob a jurisdição de uma subprefeitura, menos esta exerceria a função de coordenadoria, razão pela qual sua criação, na época, foi justificada. Desse modo, mais tênues seriam os limites que separariam e distinguiriam os dois órgãos. A rigor, no último mandato de Maia, 
$41 \%$ das subprefeituras ${ }^{20}$ estariam fora da categoria "coordenadoria das Regiões Administrativas", pois controlavam apenas uma ou nenhuma RA.

\section{Conclusão}

Como foi visto, a inovação das subprefeituras em São Paulo e Rio de Janeiro se moldou às práticas políticas institucionalizadas de barganha política dos governos municipais com vereadores que controlam regiões da cidade. Embora por rotas e tempos distintos, ao fim e ao cabo, os dois casos convergiram para o mesmo tipo de utilização das subprefeituras como recurso político para os prefeitos construírem suas coalizões políticas dominantes.

Em São Paulo, a proposta de contrabalançar o peso da democracia representativa com centros locais de poder apoiados na democracia participativa tornou-se secundária. No Rio de Janeiro, a proposta de controlar a influência dos vereadores com um grupo de subprefeitos diretamente vinculado ao prefeito não se sustentou após o primeiro mandato de Cesar Maia. Em resumo, a "lógica da vereança" se sobrepôs como a estratégia dominante em ambos os casos. Ademais, as escolhas políticas alinhadas à formação da política de alianças não respeitaram fronteiras e discursos partidários, pois PFL e PT não poderiam ser exemplares mais extremos de visões políticas divergentes.

Assim, o cotejamento da análise empírica com a questão teórica que orientou esse trabalho mostra que colorações partidárias não foram determinantes nas escolhas dos prefeitos quanto ao método para compor sua base de apoio parlamentar. Nas duas cidades, a inovação institucional proposta nas estruturas governamentais não apenas foi alimentada por práticas políticas tradicionalmente existentes como as apoiou. Com efeito, a "lógica dos vereadores", com o tempo, prevaleceu, pois as subprefeituras passaram a ser meios essenciais para os governos comporem suas coalizões de apoio na Câmara Municipal.

A experiência das duas cidades mostra a resiliência de práticas políticas institucionalizadase comoinovaçõesgerenciaisepolíticastidascomodemocratizantes, como é o caso da descentralização, podem ser funcionais aos interesses paroquiais de atores políticos, como os vereadores. Portanto, a descentralização nem sempre é virtuosa, pois pode se prestar para apoiar a patronagem com recursos públicos e reforçar as pequenas soberanias locais destacadas por Robert Dahl. Por essa razão, as subprefeituras acabaram respondendo, embora com diferenças entre as duas

\footnotetext{
${ }^{20} \mathrm{O}$ total seria de oito, considerando o caso das seis subprefeituras (Centro Histórico, Zona Sul II, Leopoldina Norte, Ilha do Governador e Zona Oeste) que se ligavam a apenas uma RA cada, além das outras duas subprefeituras (Lins Vasconcelos e Vila Militar) que não se relacionam a quaisquer regiões administrativas.
} 
cidades e mesmo em cada uma de suas regiões, a um duplo comando: o formal (administrativo) e o informal (vereador). Em linha com o argumento de Borja (1984), a divisão de poderes nas regiões refletiu o peso político que os vereadores detinham nos bairros.

A forma como a coalizão política dominante se organizou nos dois casos, centrada na liderança do prefeito nas negociações e dividindo espaços com um amplo espectro partidário, inclusive de antigos adversários políticos, mostra a relevância que assumiu a governabilidade junto às Câmaras Municipais após 1988. Não apenas os municípios ampliaram sua autonomia política e administrativa, mas também as Câmaras de Vereadores ampliaram suas prerrogativas de controle, fiscalização e mesmo como atores de veto em relação ao Poder Executivo.

Portanto, conformar políticas de aliança tornou-se condição necessária, mas não suficiente, de governabilidade. Contudo, o que este artigo discutiu não foi esse processo em si, mas sim como inovações nas estruturas de governo gradativamente se encontraram com práticas políticas institucionalizadas de patronagem governamental. Os dois casos mostram que a inovação política e administrativa nas estruturas locais e regionais de gestão foi condição suficiente para que a inovação institucional das subprefeituras fosse colocada a serviço de velhos fins. Constrangidas pelos interesses dos atores políticos (práticas políticas institucionalizadas dos vereadores) e pelas regras do jogo na relação com a Câmara Municipal, paradoxalmente as inovações propostas por prefeitos podem ser a senha para que pouco ou nada mude na política municipal.

\section{Referências bibliográficas}

ABrucio, Fernando Luiz; Couto, Cláudio Gonçalves. A redefinição do papel do Estado no âmbito local. São Paulo Perspec., v. 10, n. 3, p. 40-47, jul./set. 1996.

BORJA, J. Descentralización: una cuestión de método. Revista Mexicana de Sociologia, v. 46, n. 4, p. 5-33, out.-dez. 1984.

Coligação Muda SÃo Paulo. Programa de Governo. São Paulo, 2000.

DAHL, R. A. A critique of the Ruling Elite Model. The American Political Science Review, v. 52, n. 2, p. 463-469, jun. 1958.

. Who participates in local politics and why. American Association for the Advancement of Science, v. 134, n. 3487, p. 1340-1348, out. 1961.

Who governs? Democracy and power in a American city. New Haven and London: Yale University Press, 1989.

DINIZ, Eli. Voto e máquina política: patronagem e clientelismo no Rio de Janeiro. Rio de Janeiro: Editora Paz e Terra, 1982.

Donato, A., A descentralização em São Paulo. In GASPAR, R.; AKERMAN, M.; GARIBE, R. Espaço urbano e inclusão social: a gestão pública na cidade de São Paulo (2001- 
2004). São Paulo: Fundação Perseu Abramo, 2006.

FRISCHTAK, Leila Lucas. Governança, governabilidade e reforma. In: REIS VeLLOSO, João Paulo (Org.). Governabilidade, sistema político e violência urbana. Rio de Janeiro: José Olympio Editora, 1994. p. 194-201.

GARIBE, R. (Org.). Espaço urbano e inclusão social: a gestão pública na cidade de São Paulo (2001-2004). São Paulo: Editora Fundação Perseu Abramo, 2006. p. 35-42.

GARIBE, R. A descentralização do poder em São Paulo. In: GARIBE, R.; CAPUCCI, P. (Orgs.) Gestão local nos territórios da cidade: ciclo de atividades com as subprefeituras. São Paulo: Mídia Alternativa: Secretaria Municipal das Subprefeituras, 2004. p. 13-18.

KUGELMAS, Eduardo; SOLA, Lourdes. Recentralização/Descentralização: dinâmica do regime federativo no Brasil dos anos 90. Tempo Social-Rev. Sociol. USP, S. Paulo, v. 11, n. 2, p. 63-81, out. 1999 (editado em fev. 2000).

KUSCHNIR, Karina. O cotidiano da política. Rio de Janeiro: Jorge Zahar Editora, 2000. LAMEIRÃo, Camila R. Estratégias políticas e gestão local: as subprefeituras do Município do Rio de Janeiro. Rio de Janeiro: UFF, 2007. 127 p. Dissertação (Mestrado em Ciência Política) - Universidade Federal Fluminense (UFF), Rio de Janeiro.

LE GALÈS, P. Urban governance in Europe: what is governed? Paris: Centre d'études europénnes (mimeografado), 2010. 15 p.

LoWI, T. J. American business, public policy, case studies, and political theory. World Politics, v. 16, n. 4, p. 677-715, jul. 1964.

MARCH, J. G; OLSEN, J. P. The New Institucionalism: organizacional factors in political life. The American Political Science Review, v. 78, n. 3, p. 734-749, set. 1984.

MARques, Francisco M. da Costa. O grupo César Maia: líderes, partidos e política no Rio de Janeiro. Rio de Janeiro: UFF, 2003. Dissertação (Mestrado em Ciência Política) - Universidade Federal Fluminense (UFF), Rio de Janeiro.

MARTIns, M.L.R. Descentralização e subprefeituras em São Paulo. Disponível em: <www.usp.br/fau/depprojeto/labhab/.../martinsdescentralizaerundina.pdf.>. Acesso: 15 Jan. 2010.

Mello, Celso Antônio B. Curso de Direito Administrativo. 25. ed., revisada e atualizada até a emenda constitucional 56, de 20/12/2007. São Paulo: Malheiros Editores, 2008.

Mollenkopf, J. H. The rise and fall of the Koch coalition in New York City politics. New Jersey: Princeton University Press, 1992.

POLSBY, N.W. How to study communitiy power: the pluralist alternative. The Journal of Politics, vol. 22, n. 3, p. 474-484, ago. 1960.

Prefeitura Municipal de SÃo Paulo. Sumário de Dados 2004. São Paulo: Secretaria de Governo Municipal, 2004.

SADER, E. Governar para todos: uma avaliação da gestão Luiza Erundina. São Paulo: Scritta Editorial, 1992.

SAntos, U. P.; BARRetTA, D. As subprefeituras em São Paulo. São Paulo: Hucitec, Prefeitura Municipal de São Paulo, 2004. 
SKOCPOL, T. Bringing the State back in: strategies of analisys in current research. In: Evans, P. B.; RueschmeYeR, D.; SKOCPOL, T (Eds.). Bringing the State back in. Cambridge: Cambridge University Press, 2002. p. 3-41.

Sposati, A. A cidade em pedaços. São Paulo: Editora Brasiliense; 2001.

SPOSATI, A. Superando o discurso da descentralização municipal. In: CALDERón, A. I.; CHAIA, V. (Orgs.). Gestão municipal: descentralização e participação popular. São Paulo: Cortez, 2002. p.73-82.

TEIXEIRA, M. A. C. Negociação política e as formas de interação Executivo Legislativo no Brasil no período de 1983 a 1992. Cadernos Gestão Pública e Cidadania. São Paulo: Fundação Getulio Vargas, 2004. 76 p.

THELEN, K.; SteINMO, S. Historical institutionalism in comparative In: SteINMO, S.; THELEN, K.; LONGSTRETH, F. (Orgs.). Structuring politics: historical institutionalism in comparative analysis. Cambridge: Cambridge University Press, 1992. p. 1-32.

WEIR, M. Ideas and politics of bounded innovation. In: STEINMO, S.; THELEN, K.; LONGSTRETH, F. (Orgs.). Structuring politics: historical institutionalism in comparative analysis. Cambridge: Cambridge University Press, 1992. p. 188-216.

\section{Outras fontes}

CÂMARA Municipal de SÃo PAUlo. Lei no 13.682, de 15 de dezembro de 2003. Dispõe sobre a estrutura organizacional das Subprefeituras. . Lei Orgânica do Município de São Paulo. Disponível em:< http://www. camara.sp.gov.br/images/stories/legislacao/Lei-Organica >. Acesso:18 Jan. 2010. . Lei no 13.399, de 17 de julho de 2002. Dispõe sobre a criação de Subprefeituras no município de São Paulo.

\section{Entrevistas}

César Maia (Prefeito do Rio de Janeiro -1993/1996 e 2004/2008)

Tadeu Pais (Subprefeito da Capela do Socorro/São Paulo)

Neli Márcia Ferreira (Subprefeita da Freguesia do Ó/São Paulo)

\section{Eduardo José Grin}

Doutor em Administração Pública e Governo, pela Fundação Getúlio Vargas de São Paulo (FGV-SP). Atualmente é Professor da Escola de Administração de Empresas e da Escola de Economia da FGV-SP. Contato: eduardo.grin@ fgv.br

\section{Camila Romero Lameirão}

Doutora em Ciência Política pela Universidade Federal Fluminense (UFF). Atualmente é professora adjunta de Ciência Política da Universidade Federal de Goiás (UFG) e coordenadora do Curso de Especialização em Políticas Públicas na mesma universidade. Contato: cromero.cp@gmail.com 
RSP 